\title{
Molecular Mechanisms of Long-Term Potentiation in the Insular Cortex In Vivo
}

\author{
Matthew W. Jones, Pim J. French, T. V. P. Bliss, and Kobi Rosenblum \\ Division of Neurophysiology, National Institute for Medical Research, London NW7 1AA, United Kingdom
}

We have investigated molecular mechanisms of synaptic plasticity in the pathway between two forebrain structures important for taste learning, the basolateral amygdala (BLA) and the insular cortex. We report here that in vivo long-term potentiation (LTP) induced by BLA stimulation requires functional NMDA receptors and is modulated by muscarinic acetylcholine receptors. In addition, LTP results in the activation of cortical extracellular regulated kinase 1/2 (ERK1/2) and is blocked by inhibitors of ERK $1 / 2$ activation. Previous findings demonstrated the involvement of the same molecular mechanisms in the same cortical area during novel taste learning. The results demonstrate that both synaptic and behavioral plasticity share common molecular mechanisms in the insular cortex.

Key words: long-term potentiation; basolateral amygdala; insular cortex; muscarinic acetylcholine receptors; extracellularregulated kinases; ERK1/2; mitogen-activated protein kinase; immediate early gene
Many studies of the biological basis of memory have attempted to link neurophysiological phenomena such as long-term potentiation (LTP) with experimentally defined behaviors. LTP is an attractive model for the cellular basis of learning and memory: activity-dependent, sustained increases in synaptic efficacy hold clear parallels with changes in behavior after salient learning events (Bliss and Collingridge, 1993). LTP was first described in the hippocampus, a structure that has been implicated in various forms of learning and memory. The rodent hippocampus has most notably been linked with learning related to spatial information (Morris et al., 1986), but its specific role remains controversial. Similarly, although molecular mechanisms of synaptic plasticity in the hippocampus have been studied extensively, it is becoming evident that different mechanisms subserve different phases of LTP in different subregions (Bliss and Collingridge, 1993). We hoped to limit such complications by studying LTP and its molecular substrates in the insular cortex, a region clearly involved in well defined taste learning paradigms such as conditioned taste aversion (CTA; Garcia et al., 1955).

Rodents rely heavily on their chemical senses, making taste learning in the rat a natural and robust behavior useful for study of the anatomical, physiological, and molecular substrates of learning. The neuroanatomical structures involved in receiving and processing taste information include the brainstem, the pons, the thalamus, and two forebrain areas: the amygdala and the central gustatory area, which resides in the insular cortex (IC; Fig. $1 a$ ). Quantified behavioral paradigms of novel taste learning (e.g., CTA and latent inhibition of CTA) enable the study of molecular mechanisms of learning and memory in the above brain areas (Berman et al., 1998). Furthermore, it was reported recently that high-frequency stimulation of the basolateral amygdala (BLA) induces LTP at synapses in the IC (Escobar et al., 1998), a pathway

Received July 9, 1999; revised Aug. 18, 1999; accepted Aug. 28, 1999.

K.R. thanks the European Molecular Biology Organization and The Royal Society for support.

Correspondence should be addressed to Kobi Rosenblum, Division of Neurophysiology, National Institute for Medical Research, The Ridgeway, Mill Hill, London NW7 1AA, UK. E-mail: krosenb@nimr.mrc.ac.uk.

Copyright (C) 1999 Society for Neuroscience $\quad 0270-6474 / 99 / 190001-\bullet \$ 05.00 / 0$ involved in well defined-taste learning paradigms (Yamamoto et al., 1984).

A range of molecular changes have been described in the IC after novel taste learning. These include tyrosine phosphorylation of the 2B subunit of the NMDA receptor (Rosenblum et al., 1995), release of acetylcholine (Shimura et al., 1995), increased PKC activity (Yasoshima and Yamamoto, 1997), and increased activation of extracellular regulated kinase 1/2 (ERK1/2) (Berman et al., 1998). In addition, an obligatory role for functional NMDA receptors, muscarinic acetylcholine $(\mathrm{mACh})$ receptors, activation of MAP/ERK kinase (MEK, the kinase that specifically activates ERK1/2), and protein synthesis machinery was reported (Rosenblum et al., 1993). To establish correlations with these molecular substrates of learning, we have begun to dissect the molecular events that underlie LTP in the pathway from basolateral amygdala to insular cortex.

\section{MATERIALS AND METHODS}

Electrophysiology. All procedures were performed in accordance with the UK Home Office Animals (Scientific Procedures) Act, 1986. Adult male Wistar rats $(250-350 \mathrm{gm})$ were anesthetized with sodium pentobarbitone (initial dose, $60 \mathrm{mg} / \mathrm{kg}$, i.p.; supplementary doses of $10 \mathrm{mg} / \mathrm{kg}$ as required) and mounted in a stereotaxic frame. Body temperature was maintained at $37-38^{\circ} \mathrm{C}$ throughout. A concentric bipolar stimulating electrode was placed in the medial perforant path (PP; $4-4.2 \mathrm{~mm}$ lateral of $\lambda, 1.5-2.0 \mathrm{~mm}$ dorsal to pial surface) and a recording micropipette in the hilus of the dentate gyrus (DG; $4 \mathrm{~mm}$ caudal to bregma, $2.5 \mathrm{~mm}$ lateral, 3-3.5 mm dorsal). Once DG field potentials had been maximized,

This article is published in The Journal of Neuroscience, Rapid Communications Section, which publishes brief, peerreviewed papers online, not in print. Rapid Communications are posted online approximately one month earlier than they would appear if printed. They are listed in the Table of Contents of the next open issue of JNeurosci. Cite this article as: JNeurosci, 1999, 19:RC36 (1-8). The publication date is the date of posting online at www.jneurosci.org.

http://www.jneurosci.org/cgi/content/full/3593 
the stimulating electrode was removed from the PP (except in MK801treated animals; see below) and lowered into the BLA ( $3 \mathrm{~mm}$ caudal to bregma, $5 \mathrm{~mm}$ lateral, $7 \mathrm{~mm}$ dorsal). Successful stimulation of this amygdaloid nucleus was confirmed by evoking characteristic responses in the DG. A second recording electrode was then placed in the rostral IC (1 $\mathrm{mm}$ rostral of bregma, $5.5 \mathrm{~mm}$ lateral, $4.5 \mathrm{~mm}$ dorsal), with placement confirmed by histology in initial experiments (data not shown).

The BLA was stimulated using $60 \mu$ sec current pulses of an amplitude that evoked a $50 \%$ maximal response in the IC $(60-100 \mu \mathrm{A}$; mean $\pm \mathrm{SD}$, $81 \pm 4.6 \mu \mathrm{A})$. Test stimuli were delivered at $0.033 \mathrm{~Hz}$, and tetanic stimulation of the BLA (six trains of 100 pulses at $100 \mathrm{~Hz}, 20 \mathrm{sec}$ between trains) was delivered once a stable baseline had been established. In some animals, the same number and intensity of stimuli were given at 0.1 $\mathrm{Hz}$ to determine the effects of nonpotentiating activity on gene expression. In animals treated with MK801, the PP was tetanically stimulated (three trains of 50 pulses at $250 \mathrm{~Hz}, 30 \mathrm{sec}$ between trains) 40 min after injection to confirm that the drug was effective in blocking the induction of LTP in the hippocampus. The $0.033 \mathrm{~Hz}$ stimulation was continued for 20-60 min, according to the post-tetanic time point at which the brain was removed.

Drugs and delivery. MK801 (Tocris Cookson, Bristol, UK) and atropine (Sigma, St. Louis, MO) were dissolved in water or water mixed with a few drops of ethanol, respectively. PD98059 (Calbiochem, Nottingham, UK) was dissolved in 1:500 DMSO. An injection micropipette was placed $0.5 \mathrm{~mm}$ dorsal to the IC, and $1 \mu \mathrm{l}$ injections of either $38 \mu \mathrm{M}$ PD 98059 (test hemisphere) or $0.2 \%$ DMSO (control hemisphere) were made over 10 $\mathrm{min}$. The injection pipette was then removed and replaced by a recording micropipette.

In situ hybridization. One hour after tetanic stimulation of the BLA, brains were removed, frozen on dry ice, and stored at $-70^{\circ} \mathrm{C}$. Fourteenmicrometer-thick sections were cut on a cryostat and mounted on polyL-lysine-coated glass slides and stored at $-70^{\circ} \mathrm{C}$. In situ hybridization was performed essentially as described by Wisden et al. (1990). Briefly, sections were thawed at room temperature, fixed in $4 \%$ paraformaldehyde, actetylated in $1.4 \%$ triethanolamine and $0.25 \%$ acetic anhydride, dehydrated through graded ethanol solutions, and delipidated in chloroform. Sections were hybridized overnight at $42^{\circ} \mathrm{C}$ in $100 \mu \mathrm{l}$ of buffer containing $50 \%$ formamide, $4 \times$ SSC $(150 \mathrm{~mm}$ sodium chloride and $15 \mathrm{~mm}$ sodium citrate), $10 \%$ dextran sulfate, $5 \times$ Denhardt's solution, $200 \mu \mathrm{g} / \mathrm{ml}$ acid- and alkali-cleaved salmon testis DNA, $100 \mu \mathrm{g} / \mathrm{ml}$ long-chain polyadenylic acid, $25 \mathrm{~mm}$ sodium phosphate, $\mathrm{pH} 7.0,1 \mathrm{~mm}$ sodium pyrophosphate, and $100,000 \mathrm{cpm}$ radiolabeled probe $(\sim 1 \mathrm{ng} / \mathrm{ml})$ under Parafilm coverslips. Sections were washed in $1 \times$ SSC at room temperature, $1 \times$ $\mathrm{SSC}$ at $55^{\circ} \mathrm{C}(30 \mathrm{~min})$, and $0.1 \times \mathrm{SSC}$ at room temperature $(5 \mathrm{~min})$ and dehydrated in 70 and $95 \%$ ethanol. Sections were then exposed to autoradiographic film. ${ }^{35} \mathrm{~S}$-ATP end-labeled probes (New England Nuclear, Boston, MA) were generated using terminal deoxynucleotidyl transferase (Promega, Madison, WI) according to manufacturer's instructions (Promega) and purified over Sephadex G50 columns (Promega). A 50-fold excess of unlabeled oligonucleotide was used as a negative control. Autoradiographs were analyzed by measuring the integrated density relative to a $\mathrm{C}^{14}$ standard using the NIH Image program. Oligonucleotides of unique sequence were supplied by Oswel (Southampton, UK). Probe sequences were zif268, CCGTGGCTCAGCAGCATCATCTCCTCCAGTTTGGGGTAGTTGTCC, complementary to nucleotides spanning amino acids 2-16 (Milbrandt, 1987); c-Fos, GCAGCGGGAGGATGACGCCTCGTGTCCGCGTTGAAACCCGAGAA, complementary to nucleotides spanning amino acids 1-15 (Morgan et al., 1987); except in the experiment using PD98059, in which the virtually identical oligonucleotide against murine $c F o s$ was used; the specificity of this oligonucleotide was determined by competing with excess unlabeled rat c-Fos oligonucleotide; Arc, GTTCTTCACCGAGCCCTGTTTGAACTCCCACCACTTCTTGGCTGG, complementary to nucleotides spanning amino acids 249-263 (Lyford et al., 1995); and Homer, GTCAGTTCCATCTTCTCCTGCGACTTCTCCTTTGCCAG, complementary to nucleotides spanning amino acids 111-123 (Brakeman et al., 1997; Kato et al., 1998).

Homogenization. Thirty minutes after tetanic stimulation, rats were decapitated, and the insular cortex was excised on ice (the crossing of the rhinal fissure and the middle cerebral artery was used as a reference point). The samples were immediately homogenized in a glass-Teflon homogenizer in $300 \mathrm{ml}$ of SDS sample buffer (10\% glycerol, $5 \%$ $\beta$-mercaptoethanol, and $2.3 \%$ SDS, in $62.5 \mathrm{~mm}$ Tris-Hcl, $\mathrm{pH} \mathrm{6.8)}$ and boiled for $5 \mathrm{~min}$. Samples were stored at $-20^{\circ} \mathrm{C}$ until further use.

Western blot analysis. Similar amounts of protein (Lowry method) in
SDS-sample buffer were separated by SDS-PAGE (10\% polyacrylamide; see Laemmli,1970) and identified by Western blot analysis. After separation, the blots were blocked with $1 \% \mathrm{BSA}$ for $1 \mathrm{hr}$ at room temperature. The blots were reacted either overnight in a cold room or for $1 \mathrm{hr}$ at room temperature with primary antibody. After three short washes the blots were subsequently incubated for $1 \mathrm{hr}$ at room temperature with HRPlinked protein A or HRP-conjugated protein G (Chemicon, Temecula, CA). The blots than were exposed to ECL substrate and film (Amersham, Arlington Heights, IL). The antibodies used were dpERK (Promega; 1:30,000; New England Biolabs, Beverly, MA; 1:5000), ERK1/2 (New England Biolabs; 1:2000), and ERKII (Santa Cruz Biotechnology, Santa Cruz, CA; 1:4000). Quantification was performed using a computerized densitometer and image analyzer (Molecular Dynamics, Sunnyvale, $\mathrm{CA}$ ).

Statistics. Mean \pm SEM values are given throughout. For LTP experiments, drug effects on the level of potentiation in different groups of animals were compared using an unpaired Student's $t$ test, comparing mean values over the period indicated. A $t$ test was also used to compare densitometric Western blot analyses. Effects were considered significant at $p<0.05$.

\section{RESULTS}

Single-pulse stimulation of the BLA evoked characteristic positive-going field potentials in the DG and IC (Fig. 1b). The DG responses were biphasic at maximal stimulation intensities, with early and late components. The early component was not elicited by the test stimulus intensities used for LTP experiments; the late component had a latency of $20 \pm 1.1 \mathrm{msec}$ to peak and amplitude of $6.7 \pm 0.89 \mathrm{mV}$ at test intensity (measured during the 10 min period before the tetanus; $n=4$ ). This late component of the $\mathrm{BLA} \rightarrow \mathrm{DG}$ response reversed polarity when the recording electrode was raised to the synaptic layer of the DG (data not shown). The BLA $\rightarrow$ IC evoked potential (EP) was monophasic (mean amplitude, $0.97 \pm 0.06 \mathrm{mV}$; mean latency to peak, $12 \pm 0.5$ msec over 10 min before tetanus; $n=8$ ) and did not show clear reversal. Neither DG nor IC responses exhibited a population spike at any stimulation intensity tested. EEG was monitored throughout, and no sign of seizure was observed during any of the protocols used.

As shown in Figure 2, $a$ and $b$, tetanic stimulation of the BLA induced a stable potentiation of the $\mathrm{BLA} \rightarrow \mathrm{IC}$ response (slope increased by $43 \pm 5 \%$ and amplitude by $46 \pm 1 \%$ of control, comparing mean measurement made 50-60 min after tetanus with mean baseline responses in the $10 \mathrm{~min}$ before the tetanus). $\mathrm{BLA} \rightarrow \mathrm{IC}$ responses were not affected under these conditions, remaining within $7 \pm 5 \%$ of control levels. Block of either NMDA receptors or $\mathrm{mACh}$ receptors in the insular cortex significantly attenuates novel taste learning in the rat (Naor and Dudai,1996; Rosenblum et al., 1997). We therefore tested the dependency of this form of cortical LTP on the same two receptors. Induction of $\mathrm{LTP}_{\mathrm{BLA} \rightarrow \mathrm{IC}}$ was blocked (responses remained within $2 \pm 1 \%$ of control $10-30$ min after tetanus; $p<0.05$ ) by the irreversible NMDA receptor channel blocker MK801 (Fig. $2 b$ ), administered systemically $60 \mathrm{~min}$ before tetanic stimulation at a dose $(1 \mathrm{mg} / \mathrm{kg}$, i.p.) shown in the same animals to block induction of $\mathrm{LTP}_{\mathrm{PP} \rightarrow \mathrm{DG}}$ in the hippocampus (where $\mathrm{PP} \rightarrow \mathrm{DG}$ EPSP slope remained within $6 \pm 1 \%$ of control 5-10 min after tetanus). $\mathrm{LTP}_{\mathrm{BLA} \rightarrow \mathrm{IC}}$ was also significantly attenuated (slope only increased by $32 \pm 1 \%$ of control $10-40$ min after tetanus; $p<0.05)$ by the muscarinic ACh receptor antagonist atropine (60 $\mathrm{mg} / \mathrm{kg}$, i.p., $40 \mathrm{~min}$ before tetanus), although unlike the NMDA receptor antagonist, this dose of atropine clearly did not completely block $\operatorname{LTP}_{\mathrm{BLA} \rightarrow \mathrm{IC}}$ (Fig. 2c). Neither MK801 nor atropine affected test responses, which maintained a mean pretetanus amplitude of $1.1 \pm 0.04$ and $0.88 \pm 0.06 \mathrm{mV}$, respectively, at these 
a

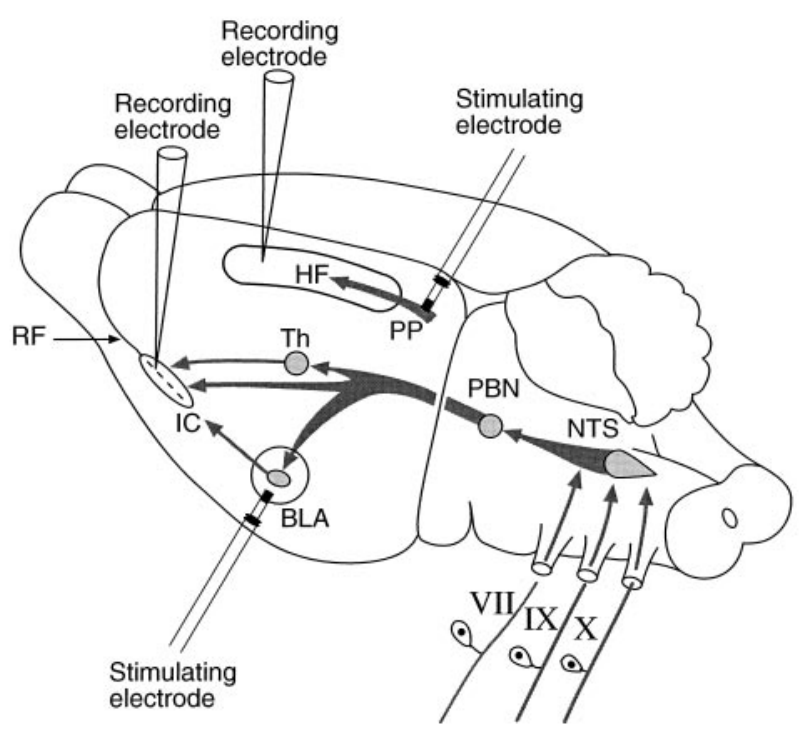

b

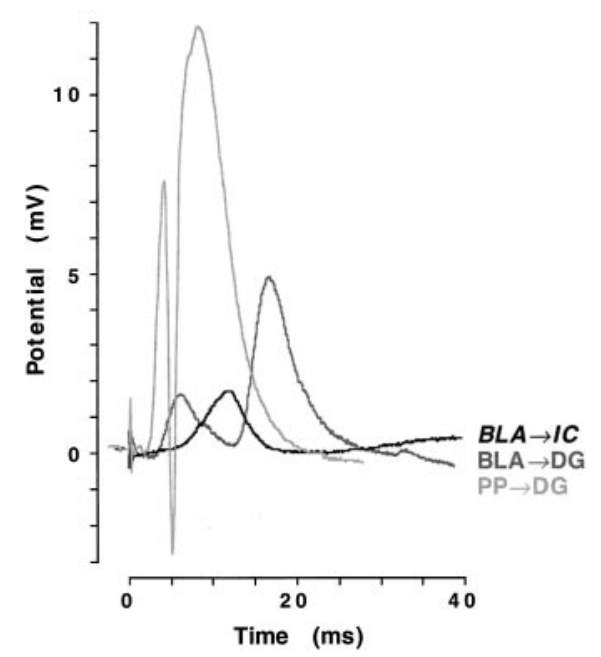

C

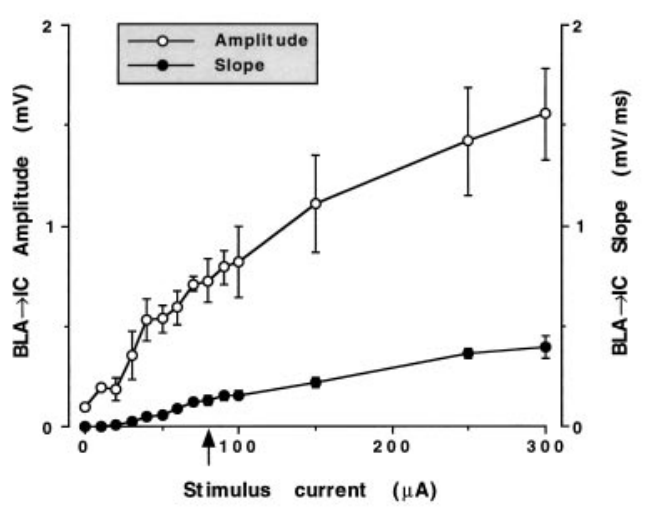

Figure 1. Anatomy and physiology of projections to and from the basolateral amygdala. a, Arrows indicate how three cranial nerves carry taste information from the oral cavity to the nucleus tractus solitaruis (NTS) in the brainstem. From there, the information flows to the parabrachial nucleus $(P B N)$ of the pons, specific regions of the thalamus $(T h)$, and forebrain areas including the amygdala and the IC. We have studied connections from the BLA, to the dentate gyrus of the hippocampal formation $(H F)$, and to the IC. Field potentials were evoked in the dentate doses (compared with the control response amplitude of $0.97 \pm$ $0.06 \mathrm{mV}$, values given as mean for $5 \mathrm{~min}$ before tetanus). This suggests that $\mathrm{BLA} \rightarrow \mathrm{IC}$ low-frequency synaptic transmission was not affected by systemic administration of these antagonists.

Because both ACh receptor and NMDA receptor activation induce ERK1/2 activation in primary cortical cultures (K. Rosenblum and M. Futter, unpublished data), and ERK1/2 activation is correlated with novel taste learning in the insular cortex (Rosenblum et al., 1995), we next investigated the involvement of the enzymes ERK1/2 in this form of LTP. ERK1/2 belong to the mitogen-associated protein kinase (MAPK) family of serine/threonine kinases and are highly expressed in the mature CNS (Fukunaga and Miyamoto, 1998). MAPKs take part in transmembrane signaling cascades, conveying information from extracellular receptor proteins to cytoplasm and nucleus. MAPKs are well established as playing a crucial role in differentiation, proliferation, and development and have recently been implicated in learning and memory-related plasticity in different species (Orban et al., 1999). ERK1/2 activation (via dual phosphorylation on Thr-201 and Tyr-203 by MEK) is correlated with novel taste learning and has been reported to underlie long-term but not short-term memory (Berman et al., 1998). We tested the possibility that ERK1/2 are activated after LTP $_{\mathrm{BLA} \rightarrow \text { IC }}$ and that activation occurred with a time course similar to that previously observed after learning (Berman et al., 1998). Consistent with previous findings, $30 \mathrm{~min}$ after the induction of $\mathrm{LTP}_{\mathrm{BLA} \rightarrow \mathrm{IC}}$ there was a significant activation of ERK1/2 in the IC $(1.7 \pm 0.1$-fold greater activation than in the unstimulated, contralateral IC) without change in the amount of ERK1/2 protein expressed in this region (Fig. $3 a)$. Using a specific inhibitor of MAPK kinase (MEK), the upstream kinase required for ERK1/2 activation, we tested whether ERK1/2 activation was required for $\mathrm{LTP}_{\mathrm{BLA} \rightarrow \mathrm{IC}}$. Microinjection of the specific MEK inhibitor PD948059 (Alessi et al., 1995) into the IC 30 min before tetanic stimulation of BLA blocked the induction of stable LTP. Although some posttetanic potentiation (to $128 \pm 1.5 \%$ of control $0-10$ min after tetanus) was evident under these conditions, responses were not significantly potentiated 30-40 min after the tetanus (Fig. $3 b)$. PD98059 had no effect on test response amplitude (1.05 \pm $0.15 \mathrm{mV}$ compared with the control response amplitude of $0.97 \pm 0.06 \mathrm{mV})$. These results parallel those obtained in an in vivo study of LTP in the hippocampus, in which we observed a block of LTP by PD98059 with a similar time course (K. Rosenblum and M. W. Jones, unpublished data).

One hypothesis regarding the maintenance of long-term plasticity suggests that modulation of gene expression is required to support remodeling of synaptic efficacy and/or morphology (Frey

$\leftarrow$

gyrus by stimulation of the PP. The crossing of the rhinal fissure $(R F)$ and middle cerebral artery was used as a guide for dissection of the IC. $b$, Characteristic field potentials recorded in the hilus of the dentate gyrus during single-pulse stimulation of the medial perforant path $(P P \rightarrow D G ; 80$ $\mu \mathrm{A}, 60 \mu \mathrm{sec})$ or basolateral amygdala $(B L A \rightarrow D G ; 150 \mu \mathrm{A}, 60 \mu \mathrm{sec})$. These responses were used to establish the correct position of the BLAstimulating electrode so that a second recording electrode could be used to record the field potential evoked in the insular cortex by BLA stimulation $(B L A \rightarrow I C ; 80 \mu \mathrm{A}, 60 \mu \mathrm{sec}) . c$, Stimulus-response curves for EP1, the field potential evoked in the IC by stimulation of the BLA $(n=3)$. Sixty microsecond stimulus pulses of increasing current were given at 10 sec intervals, evoking responses of increasing slope and amplitude. The arrow on the horizontal axis marks mean test intensity used for LTP experiments. 
a
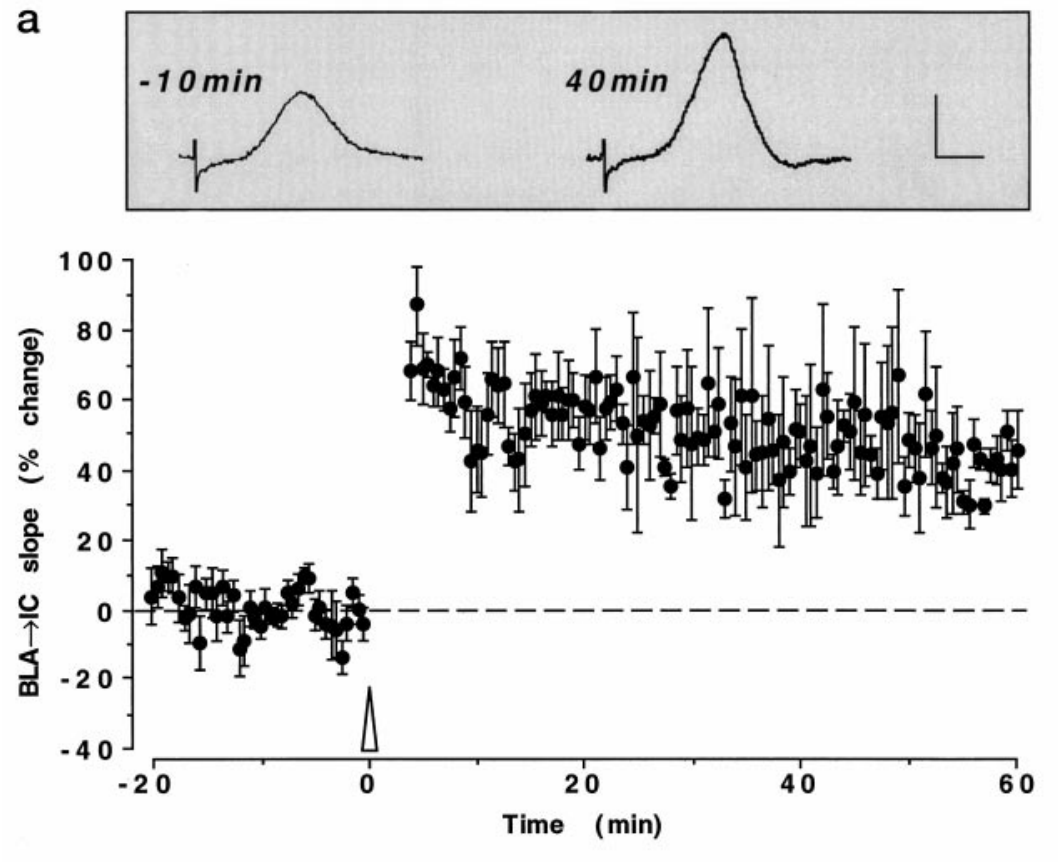

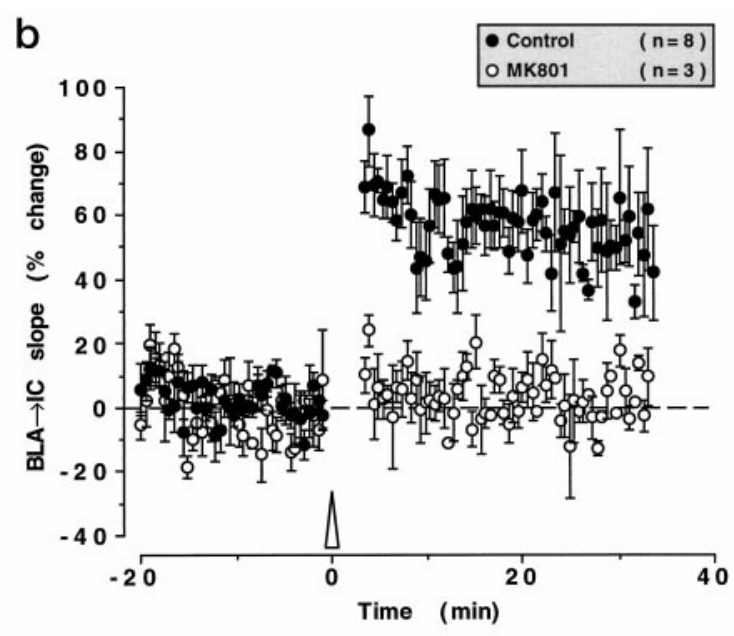

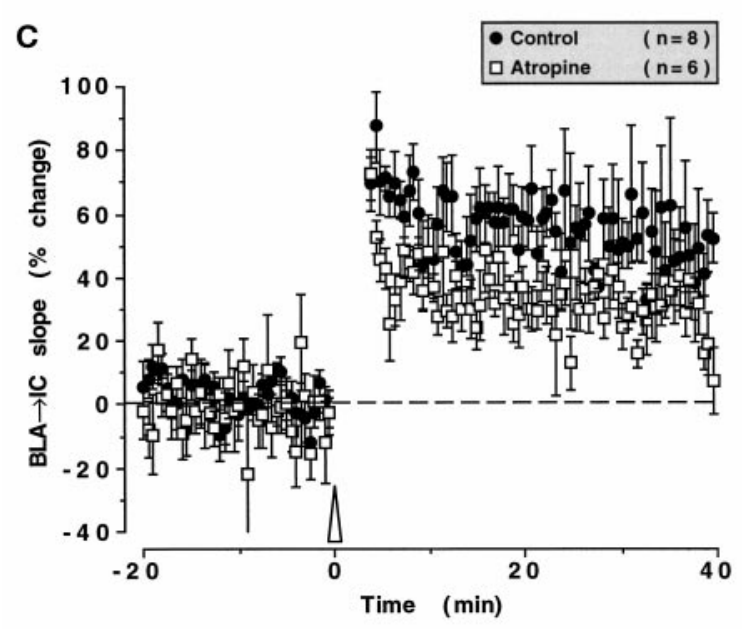

Figure 2. Long-term potentiation induced by tetanic stimulation of the BLA. $a$, Test responses were evoked 1 per $30 \mathrm{sec}$ at a test intensity that elicited a halfmaximal EP1 slope. Once responses had stabilized, six trains of 100 test intensity pulses at $100 \mathrm{~Hz}, 20 \mathrm{sec}$ between trains, were delivered to the BLA (arrowhead, time 0 ), and responses were followed for up to $60 \mathrm{~min}$. Percent changes in BLA $\rightarrow$ IC slope are plotted $(n=8)$. Representative responses taken $10 \mathrm{~min}$ before $(-10 \mathrm{~min})$ and $40 \mathrm{~min}$ after (40min) the tetanus are also shown Calibration: $1 \mathrm{mV}, 5 \mathrm{msec} . b$, $c$, LTP was completely blocked by systemic MK801 (b) (1 mg/kg, i.p., injected 60 min before tetanus) and significantly attenuated by atropine $(c)(60 \mathrm{mg} / \mathrm{kg}$, i.p., 40 min before tetanus; $p<0.0510-40$ min after tetanus).

et al., 1988). Thus in biochemical terms, late-phase LTP, like long-term memory, can be distinguished from earlier phases by a dependence on protein synthesis. Because taste learning has itself been shown to be protein synthesis-dependent (Rosenblum et al., 1993), and the MEK inhibitor PD98059 specifically blocks longbut not short-term novel taste memory (Berman et al., 1998), we tested the possibility that $\mathrm{LTP}_{\mathrm{BLA} \rightarrow \mathrm{IC}}$ is correlated with altered gene expression. The genes studied were immediate early genes (IEGs) whose induction is correlated with synaptic activity: Zif268, Fos, Arc, and Homer. Zif 268 and Fos are transcription factors (Dragunow, 1996); Arc is associated with the cytoskeleton (Steward et al., 1998); and Homer binds metabotropic glutamate receptors (Brakeman et al., 1997).

In situ hybridization showed that the expression of Zif268, Fos, Homer, and Arc mRNAs was markedly upregulated throughout the majority of cortical areas, including IC, $1 \mathrm{hr}$ after tetanic stimulation of the BLA (Fig. 4). Low-frequency stimulation of the BLA (such that the total number of stimuli delivered was identical to that required to induce potentiation when given at $100 \mathrm{~Hz}$ ) also increased IEG mRNA expression (data not shown).
Neither nonstimulated contralateral hemispheres nor any subcortical area (e.g., caudate putamen) showed any clear change nor, interestingly, did the cells of the hippocampal formation, despite the sizeable responses evoked here by BLA stimulation. It is possible that the expression of different genes is altered in these areas at time points other than $1 \mathrm{hr}$ after BLA stimulation. If so, later time points would seem more likely, because Zif268 upregulation in the hippocampus is rapid and peaks $1 \mathrm{hr}$ after tetanic stimulation of the perforant path (Wisden et al., 1990). Whereas the NMDA receptor channel blocker MK801 completely blocked $\mathrm{LTP}_{\mathrm{BLA} \rightarrow \mathrm{IC}}$, it did not block IEG upregulation, although the increase in expression was clearly attenuated. The mACh receptor antagonist atropine had effects similar to those of MK801 on IEG expression, whereas it failed to block LTP completely.

\section{DISCUSSION}

Taste-learning paradigms have recently been used to investigate specific molecular mechanisms associated with learning in the rat. The emerging picture points to the involvement of glutamatergic and cholinergic neurotransmission (via NMDA and $\mathrm{mACh}$ re- 

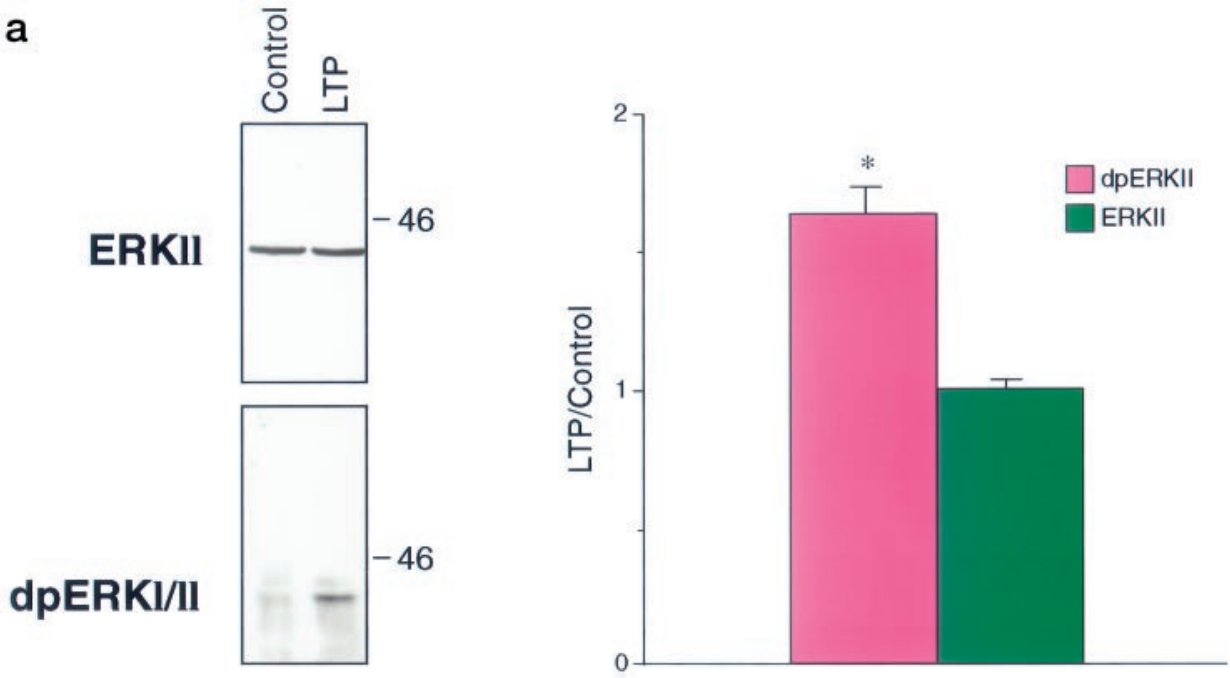

b

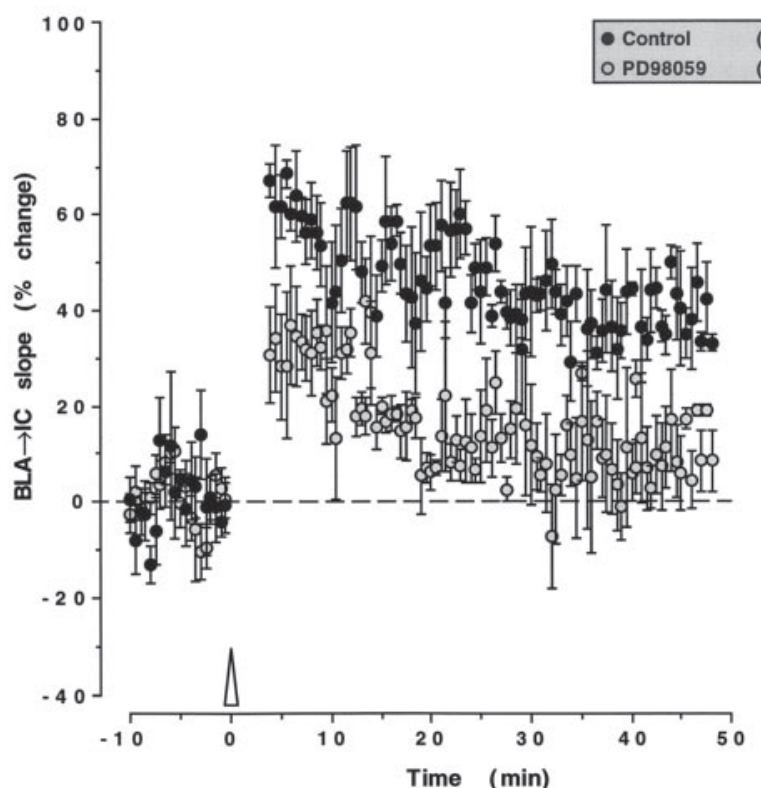

ceptors, respectively), the activation of tyrosine kinases and MAPK, and a requirement for protein synthesis (Rosenblum et al., 1993, 1997; Shimura et al., 1995). It is important to note that it is the combination of the percept itself, i.e., the taste, and its value, i.e., novelty, that induces the correlative molecular changes observed. These changes occurred specifically in the insular cortex, the central gustatory area (Braun et al., 1982). Here we show that NMDA receptors, $\mathrm{mACh}$ receptors, and members of the MAPK family ERK1/2 also subserve synaptic plasticity in the same neocortical area.

Lesion studies confirm a role for the IC and its connections to the BLA in taste learning (Bermudez-Rattoni and McGaugh, 1991) (see Fig. 1). Retrograde labeling with horseradish peroxidase suggests direct and reciprocal BLA-IC connections (Ottersen, 1982). Single-unit recording in the IC reveals neurons with a range of response latencies after electrical stimulation of the BLA (Yamamoto et al., 1984). Single-pulse stimulation of the BLA evokes reproducible, positive-going field potentials in the IC (Fig. 1b). Although not definitive, the latency of these responses

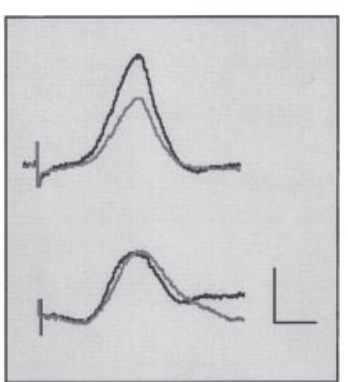

Figure 3. ERK1/2 activation is correlated with and necessary for $\mathrm{LTP}_{\mathrm{BLA} \rightarrow \mathrm{IC}} \cdot a$, Thirty minutes after the induction of LTP, the insular cortex was dissected out and processed for SDS-PAGE and immunoblotting with antiphosphospecific antibodies (Thr-201-Tyr-203) recognizing the activated form of ERK1/2 or with anti ERKII recognizing the ERKII polypeptide. Blots were analyzed using a densitometer, and the ratio between the signal on the potentiated versus the control insular cortex was calculated. Significant increases in ERK1/2 activation were observed in potentiated tissue $\left(n=4 ;{ }^{*} p<0.05\right)$. Sample blots for ERKII (top) and dpERK1/2 (bottom) are shown on the left. $b$, Microinjection of $1 \mu \mathrm{l}$ of $38 \mu \mathrm{M}$ PD $980590.5 \mathrm{~mm}$ above the insular cortex 30 min before tetanic stimulation of the BLA (arrowhead, time 0; as for Fig. 1) prevents long-lasting potentiation of IC responses. The right panel shows superimposed sample responses recorded $10 \mathrm{~min}$ before (gray) and 40 min after (black) tetanus in a control rat and a PD98059injected rat (top and bottom traces, respectively). Calibration: $1 \mathrm{mV}, 5 \mathrm{msec}$. is consistent with a monosynaptic connection, as is the block of $\mathrm{LTP}_{\mathrm{BLA} \rightarrow \mathrm{IC}}$ by local injection of PD98059 (Fig. 3b).

We confirm the observations of Escobar et al. (1998) that tetanic stimulation of the BLA results in a long-lasting enhancement of IC responses. This potentiation is maintained for at least $1 \mathrm{hr}$ (Fig. 2a) but could be followed for up to $3 \mathrm{hr}$ without decrement (data not shown). $\mathrm{LTP}_{\mathrm{BLA} \rightarrow \mathrm{IC}}$ shares properties with LTP in the hippocampus and other cortical regions, including rapid induction by $100 \mathrm{~Hz}$ stimulation, persistence, and NMDA receptor dependence (Bliss and Lømo 1973; Jay et al., 1995), although this is in contrast to some reports of slowly developing LTP in the cortex in vivo (Trepel and Racine, 1998). Responses evoked in the DG by BLA stimulation have been characterized previously (Ikegaya et al., 1996). Stimulation of the amygdala (including the BLA) has also been shown to affect $\mathrm{LTP}_{\mathrm{PP} \rightarrow \mathrm{DG}}$, a possible mechanism for modulation of hippocampal-dependent learning (Ikegaya et al., 1995, 1997). This may point to a more general role of the amygdala in signaling novelty or salience (Dunn and Everitt, 1988). 
a
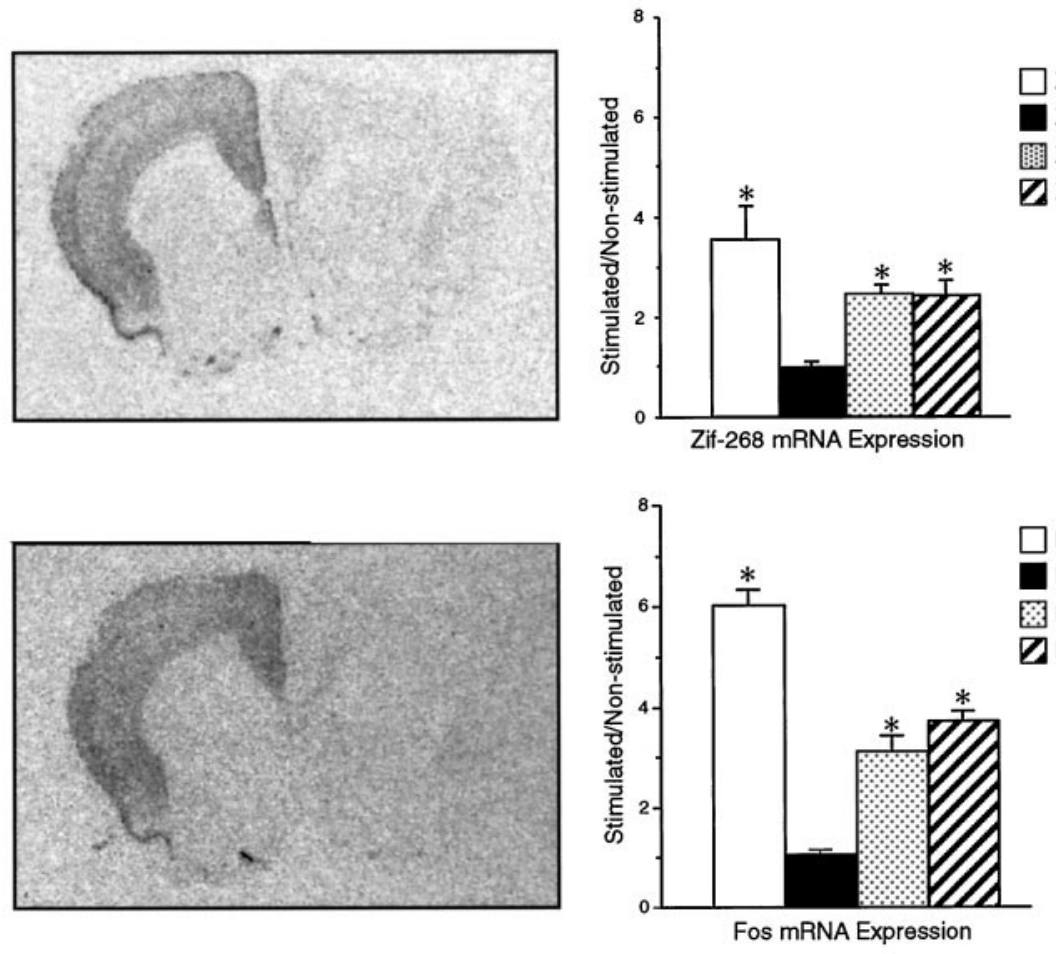

BLA induces immediate early gene en in the cortex. $a$, One hour after tetanic stimulation of the BLA and confirmed induction of LTP (see Fig. 2) in the insular cortex, brains were removed and frozen on dry ice. Sections were taken from the area containing the insular cortex or the hippocampus, and in situ hybridization was performed with oligonucleotides specific to Zif268 and Fos. As shown by the representative sections on the left, levels of Zif268 and Fos mRNA expression were increased in much of the cortex of the stimulated hemisphere but not in the nonstimulated contralateral cortex. There was no increased expression in the caudate putamen (CPU) or other noncortical areas. The histogram represents the mean ratios obtained by dividing densitometric measures from the same areas in the ipsilateral and contralateral hemispheres $(n=3$ or 4$)$. In the animals treated with MK801 or atropine (see Fig. $2 c, d$ ), the increase in Zif268 and Fos mRNA expression was attenuated but not abolished. $b$, mRNA expression of the immediate early genes $A r c$ and Homer was significantly increased in the same regions $1 \mathrm{hr}$ after tetanic stimulation of the BLA. No induction of any of the mRNAs described above was observed in the dentate gyrus of the hippocampus after BLA stimulation (data not shown). ${ }^{*} p<0.05$ for comparison between hemispheres.

b
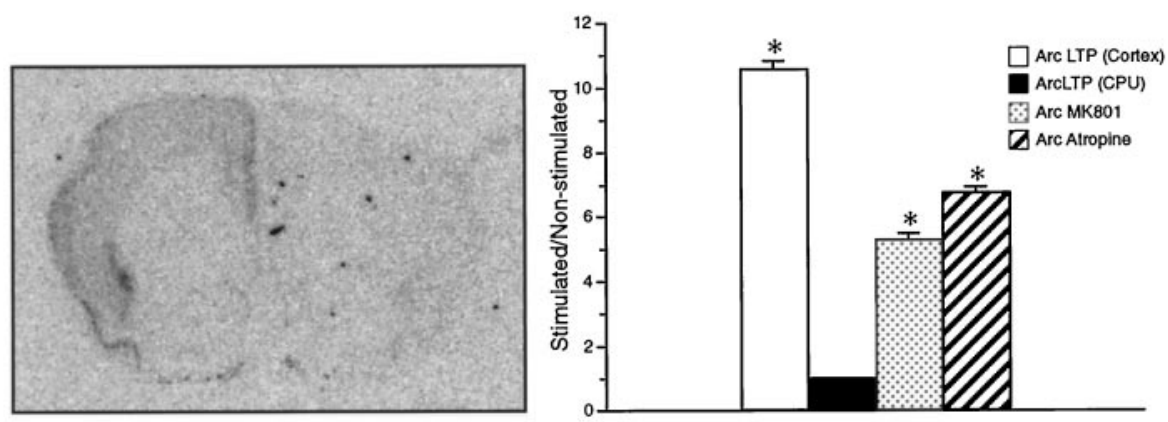

Arc mRNA Expression
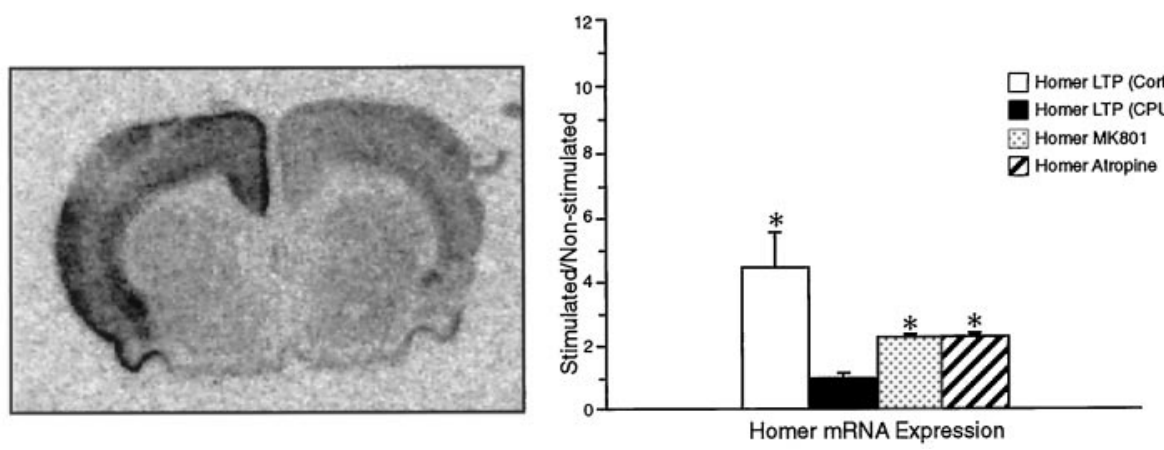

Cholinergic transmission at the $\mathrm{mACh}$ receptor has been implicated in learning and memory in humans and other mammals (Levey, 1996; Mesulam, 1998), particularly with respect to the encoding of salient input (Acquas et al., 1996). In vitro studies have shown that $\mathrm{mACh}$ receptors can modulate, or even induce, synaptic plasticity in the CA1 region of the hippocampus (Blitzer et al., 1990; Auerbach and Segal, 1994); it is not known whether this occurs in the hippocampus in vivo. Our results show that the $\mathrm{mACh}$ receptor antagonist atropine attenuates $\mathrm{LTP}_{\mathrm{BLA} \rightarrow \mathrm{IC}}$ (Fig.
$2 d$ ). This is the first demonstration of cholinergic modulation of LTP in the neocortex in vivo. NMDA and $\mathrm{mACh}$ receptors, both shown here to be important for $\mathrm{LTP}_{\mathrm{BLA} \rightarrow \mathrm{IC}}$, can activate ERK1/2 in primary cortical culture (Rosenblum and Futter, unpublished data). Indeed, $\mathrm{LTP}_{\mathrm{BLA} \rightarrow \mathrm{IC}}$ is associated with ERK1/2 activation (Fig. 3). Thus ERK1/2 could serve as a detector for coincident activation of $\mathrm{mACh}$ receptors and glutamate receptors.

In this paper we demonstrate a necessary role for ERK activa- 
tion in neocortical LTP in vivo (Fig. 3). We have also found that LTP in the DG of the hippocampus in vivo is dependent on ERK1/2 (our unpublished data). It has been suggested that MAPK is likely to play a fundamental role in memory consolidation (Blum et al., 1999; Impey et al., 1999). However, the time scales of the activation of ERK1/2 and the effects of PD98059 in both the neocortex in vivo (Fig. $3 b$ ) and in the hippocampus in vivo and in vitro (English and Sweatt, 1997; Atkins et al., 1998) suggest an action on the early phase(s) of LTP. Given the range of potential cytosolic and nuclear effects of ERK, including the modulation of gene transcription in neurons via the proteins cAMP response element-binding protein and RSK (Impey et al., 1999; Roberson et al., 1999), it seems reasonable to suppose that ERK1/2 may also have a role to play in the late, protein synthesisdependent phase of LTP.

Immediate early genes are potential targets for the modulatory activity of ERK. One such gene is the transcription factor Zif268, which shows expression correlated with NMDA receptormediated LTP but not with low-frequency activity, in the DG (Cole et al., 1989; Wisden et al., 1990). In the DG, stimulation of the perforant path leads to upregulation of mRNA for Zif268 only if the stimulation induces LTP; in contrast, stimulation of the BLA, whether it leads to LTP, can upregulate Zif268 message. As with Zif268, strong activation of Fos, Arc, and Homer mRNA expression was observed throughout most of the ipsilateral cerebral cortex after high-frequency stimulation of the BLA (Fig. 4). Again, this activation was not correlated simply with the degree of resulting potentiation, because the NMDA receptor antagonist MK801 only attenuated the increased mRNA expression but completely blocked LTP; moreover, low-frequency stimulation also induced increased transcription. It remains unclear how and why different activity in different brain areas is correlated with IEG expression. However, the extent to which BLA stimulation influences cortical IEG expression may reflect the importance of the amygdala in modulating neocortical function.

We demonstrate here that LTP shares some of the same molecular mechanisms as learning in the mature neocortex. The physiological role of LTP in learning and memory remains to be fully established, but in view of the observation that an LTP-like phenomenon is detected in the amygdala after fear conditioning (Rogan et al., 1997), it will be interesting to explore the possibility that novel taste learning induces changes in the strength of connections between the basolateral amygdala and the insular cortex.

\section{REFERENCES}

Acquas E, Wilson C, Fibiger HC (1996) Conditioned and unconditioned stimuli increase frontal cortical and hippocampal acetylcholine release: effects of novelty, habituation, and fear. J Neurosci 16:3089-3096.

Alessi DR, Cuenda A, Cohen P, Dudley DT, Saltiel AR (1995) PD 098059 is a specific inhibitor of the activation of mitogen-activated protein kinase kinase in vitro and in vivo. $\mathrm{J}$ Biol Chem 270:27489-27494.

Atkins CM, Selcher JC, Petraitis JJ, Trzaskos JM, Sweatt JD (1998) The MAPK cascade is required for mammalian associative learning. Nat Neurosci 1:602-609.

Auerbach JM, Segal M (1994) A novel cholinergic induction of longterm potentiation in rat hippocampus. J Neurophysiol 72:2034-2040.

Berman DE, Hazvi S, Rosenblum K, Seger R, Dudai Y (1998) Specific and differential activation of mitogen-activated protein kinase cascades by unfamiliar taste in the insular cortex of the behaving rat. J Neurosci 18:10037-10044.

Bermudez-Rattoni F, McGaugh JL (1991) Insular cortex and amygdala lesions differentially affect acquisition on inhibitory avoidance and conditioned taste aversion. Brain Res 549:165-170.
Bliss TVP, Collingridge GL (1993) A synaptic model of memory: longterm potentiation in the hippocampus. Nature 361:31-39.

Bliss TV, Lomo T (1973) Long-lasting potentiation of synaptic transmission in the dentate area of the anaesthetized rabbit following stimulation of the perforant path. J Physiol (Lond) 232:331-356.

Blitzer RD, Gil O, Landau EM (1990) Cholinergic stimulation enhances long-term potentiation in the CA1 region of rat hippocampus. Neurosci Lett 119:207-210.

Blum S, Moore AN, Adams F, Dash PK (1999) A mitogen-activated protein kinase cascade in the CA1/CA2 subfield of the dorsal hippocampus is essential for long-term spatial memory. J Neurosci 19:3535-3544.

Brakeman PR, Lanahan AA, O'Brien R, Roche K, Barnes CA, Huganir RL, Worley PF (1997) Homer: a protein that selectively binds metabotropic glutamate receptors. Nature 386:284-288.

Braun JJ, Lasiter PS, Kiefer SW (1982) The gustatory neocortex of the rat. Physiol Psychol 10:13-45.

Cole AJ, Saffen DW, Baraban JM, Worley PF (1989) Rapid increase of an immediate early gene messenger RNA in hippocampal neurons by synaptic NMDA receptor activation. Nature 340:474-476.

Dragunow M (1996) A role for immediate-early transcription factors in learning and memory. Behav Genet 26:293-299.

Dunn LT, Everitt BJ (1988) Double dissociations of the effects of amygdala and insular cortex lesions on conditioned taste aversion, passive avoidance and neophobia in the rat using the excitotoxin ibotenic acid. Behav Neurosci 102:3-23.

English JD, Sweatt JD (1997) A requirement for the mitogen-activated protein kinase cascade in hippocampal long term potentiation. J Biol Chem 272:19103-19106.

Escobar ML, Chao V, Bermudez-Rattoni F (1998) In vivo long-term potentiation in the insular cortex: NMDA receptor dependence. Brain Res 779:314-319.

Frey U, Krug M, Reymann KG, Matthies H (1988) Anisomycin, an inhibitor of protein-synthesis, blocks late phases of ltp phenomena in the hippocampal ca1 region in vitro. Brain Res 452:57-65.

Fukunaga K, Miyamoto E (1998) Role of MAP kinase in neurons. Mol Neurobiol 16:79-95.

Garcia J, Kimmeldorf DJ, Koelling RA (1955) Conditioned aversion to saccharin resulting from exposure to gamma radiation. Science 122:157-158.

Ikegaya Y, Saito H, Abe K (1995) High-frequency stimulation of the basolateral amygdala facilitates the induction of long-term potentiation in the dentate gyrus in-vivo. Neurosci Res 22:203-207.

Ikegaya Y, Saito H, Abe K (1996) Dentate gyrus field potentials evoked by stimulation of the basolateral amygdaloid nucleus in anesthetized rats. Brain Res 718:53-60.

Ikegaya Y, Nakanishi K, Saito H, Abe K (1997) Amygdala betanoradrenergic influence on hippocampal long-term potentiation in vivo. NeuroReport 8:3143-3146.

Impey S, Obrietan K, Storm DR (1999) Making new connections: role of ERK/MAP kinase signalling in neuronal plasticity. Neuron 23:11-14.

Jay TM, Burette F, Laroche S (1995) NMDA receptor-dependent longterm potentiation in the hippocampal afferent fibre system to the prefrontal cortex in the rat. Eur J Neurosci 7:247-250.

Kato A, Ozawa F, Saitoh Y, Fukazawa Y, Sugiyama H, Inokuchi K (1998) Novel members of the Vesl/Homer family of PDZ proteins that bind metabotropic glutamate receptors. J Biol Chem 273:23969-23975.

Laemmli UK (1970) Cleavage of structural proteins during the assembly of the head of bacteriophage $T_{4}$. Nature 227:680-685.

Levey AI (1996) Muscarinic acetylcholine receptor expression in memory circuits: implications for treatment of Alzheimer disease. Proc Natl Acad Sci USA 93:13541-13546.

Lyford GL, Yamagata K, Kaufmann WE, Barnes CA, Sanders LK, Copeland NG, Gilbert DJ, Jankins NA, Lanahan AA, Worley PF (1995) Arc, a growth factor and activity-regulated gene, encodes a novel cytoskeleton-associated protein that is enriched in neuronal dendrites. Neuron 14:433-445.

Mesulam MM (1998) Some cholinergic themes related to Alzheimer's disease: synaptology of the nucleus basalis, location of $\mathrm{m} 2$ receptors, interactions with amyloid metabolism, and perturbations of cortical plasticity. J Physiol (Paris) 92:293-298.

Milbrandt J (1987) A nerve growth factor induced gene encodes a possible transcriptional regulatory factor. Science 238:797-799.

Morgan JI, Cohen DR, Hempstaed JL, Curran T (1987) Mapping pat- 
terns of c-fos expression in the central nervous system after seizure. Science 237:192-197.

Morris RGM, Anderson E, Lynch GS, Baudry M (1986) Selective impairment of learning and blockade of long-term potentiation by an $N$-methyl-D-aspartate receptor antagonist, AP5. Nature 319:774-776.

Naor C, Dudai Y (1996) Transient impairment of cholinergic function in the rat insular cortex disrupts the encoding of taste in conditioned taste aversion. Behav Brain Res 79:61-67.

Orban PC, Chapman PF, Brambilla R (1999) Is the Ras-MAPK signalling pathway necessary for long-term memory formation? Trends Neurosci 22:38-44.

Ottersen OP (1982) Connections of the amygdala of the rat IV: corticoamygdaloid and intra-amygdaloid connections as studied with axonaltransport of horseradish-peroxidase. J Comp Neurol 205:30-48.

Roberson ED, English JD, Adams JP, Selcher JC, Kondratick C, Sweatt JD (1999) The mitogen-activated protein kinase cascade couples PKA and $\mathrm{PKC}$ to cAMP response element binding protein phosphorylation in area CA1 of hippocampus. J Neurosci 19:4337-4348

Rogan MT, Staubli UV, LeDoux JE (1997) Fear conditioning induces associative long-term potentiation in the amygdala. Nature 390:604-607.

Rosenblum K, Meiri N, Dudai Y (1993) Taste memory-the role of protein-synthesis in gustatory cortex. Behav Neural Biol 59:49-56.

Rosenblum K, Schul R, Meiri N, Hadari YR, Zick Y, Dudai Y (1995)
Modulation of protein tyrosine phosphorylation in rat insular cortex after conditioned taste aversion training. Proc Natl Acad Sci USA 92:1157-1161.

Rosenblum K, Berman DE, Hazvi S, Lamprecht R, Dudai Y (1997) NMDA receptor and the tyrosine phosphorylation of its $2 \mathrm{~B}$ subunit in taste learning in the rat insular cortex. J Neurosci 17:5129-5135.

Shimura T, Suzuki M, Yamamoto T (1995) Aversive taste stimuli facilitate extracellular acetylcholine-release in the insular gustatory cortex of the rat-a microdialysis study. Brain Res 679:221-226.

Steward O, Wallace CS, Lyford GL, Worley PF (1998) Synaptic activation causes the mRNA for the IEG Arc to localise selectively near activated postsynaptic sites on dendrites. Neuron 21:741-751.

Trepel C, Racine RJ (1998) Long-term potentiation in the neocortex of the adult, freely moving rat. Cereb Cortex 8:719-729.

Wisden W, Errington ML, Williams S, Dunnett SB, Waters C, Hitchcock D, Evan G, Bliss TV, Hunt SP (1990) Differential expression of immediate early genes in the hippocampus and spinal cord. Neuron 4:603-604

Yamamoto T, Azuma S, Kawamura Y (1984) Functional relations between the cortical gustatory area and the amygdala-electrophysiological and behavioral-studies in rats. Exp Brain Res 56:23-31.

Yasoshima Y, Yamamoto T (1997) Rat gustatory memory requires protein kinase $\mathrm{C}$ activity in the amygdala and cortical gustatory area. NeuroReport 8:1363-1367. 